\title{
The Gut Microbiota and Epigenetics
}

\author{
Kenneth Lundstrom*
}

\author{
PanTherapeutics, Rue des Remparts 4, CH1095 Lutry, Switzerland
}

\begin{abstract}
The human gut microbiota presents a strong influence on health and disease development. Metagenomic analysis has revealed the importance of the interaction between the genomes of food, gut microbiota and the host. Also, the establishment of humanized mouse gut microbiota in appropriate animal models has further contributed to the understanding of its function. The composition of the gut microbiota presents a significant impact on the risk of disease development supported by findings of substantial individual variations. Many low molecular weight bacterial substances have been indicated to affect chromatin remodeling, regulation of apoptosis, cellular differentiation and inflammation. The gut microbiota has also been linked to the etiology of cancer because of how it can alter dietary exposures. Furthermore, microbial metabolites have been associated with epigenetic modifications, reversible heritable changes in gene expression without alterations in the primary DNA sequence, which may influence the risk of various cancers and other diseases. As many microbial metabolites are absorbed into systemic circulation, gene expression might also be affected in distal regions of the gut. Therefore, the interaction of dietary intake, gut microbiota and epigenetic modifications plays an important role in disease risk, development and prevention.
\end{abstract}

Keywords: Gut microbiota, nutrition, disease, epigenetics.

\section{INTRODUCTION}

The role of the human microbiome in relation to disease development has been overlooked to some extent. Especially, the gut inhabits a large variety of bacteria, which provide a significant contribution to the metabolism of different classes of food [1]. The human gastrointestinal tract accommodates approximately 100 trillion bacteria, which have established a symbiotic relationship with the host [2]. However, it has been a major challenge to identify the composition of the gut microbiota, but improvement of DNA-based analysis has substantially accelerated the task. The understanding of the function of the microbiota has been by far more challenging. For instance, bacteria produce low molecular weight substances, which may interact with the cellular environment thereby potentially modulating signaling pathways and regulating gene expression. Obviously, the composition of the gut microbiota influences substantially these functions and significant differences in individual composition of the microbiota have been demonstrated to affect the risk of disease development [3]. Many low molecular weight substances have been indicated to be involved in chromatin remodeling, regulation of apoptosis, cellular differentiation as well as inflammation.

Interestingly, the microbiota has also been linked to epigenetic modifications. Although the phenomenon epigenetics was described by Conrad Waddington in the 1950s [4], suggesting the inheritance of a

${ }^{*}$ Correspondence address to this author at PanTherapeutics, Rue des Remparts 4, CH1095 Lutry, Switzerland; Tel: +41 79776 6351;

E-mail: lundstromkenneth@gmail.com characteristic acquired in a population in response to an environmental stimulus, its importance has become evident only in recent years. Epigenetics is defined as the study of heritable but reversible changes in the expression of genes without modifications of the primary DNA sequence [5]. The most common epigenetic changes relate to DNA methylation, histone modifications and RNA interference (RNAi). In the context of DNA methylation, a methyl group $\left(\mathrm{CH}_{3}\right)$ is covalently added to the 5'-position of cytosine upstream of guanosine, which contributes to the regulation of gene expression [6]. Methylated CpG dinucleotides are located in the promoter regions of genes and affects mRNA transcription showing association to cancer $[7,8]$. For example, hypermethylation in the promoter region has been linked to inactivation of the HIC1, INK4b and TIMP3 suppressor genes [9]. For this reason, DNA methyltransferase (DNMT) inhibitors have been developed as therapeutics in oncology [10]. Related to histone modifications, increased acetylation can result in transcription activation and histone methylation can lead to either activation or repression of transcription [11]. Furthermore, histone deacetylase (HDAC) inhibitors have been used for therapeutic interventions individually [12] or in combination with DNMT inhibitors [13]. The third epigenetic modification relating to RNAi involves particularly splicing of microRNA (miRNA), where 21-23 nucleotide singlestranded RNA molecules interfere with mRNA affecting the regulation of gene expression [14]. Depending on which miRNA is targeted, up- or down-regulation of gene expression has been observed. Today, more than 1800 miRNAs have been deposited in databases [15], of which a large number have been associated with disease $[14,16]$. 
In this review, the focus is on the impact, which the gut microbiota has on epigenetics and how dietary intervention can influence the composition on the microbiome in general and in relation to disease development and its prevention.

\section{INVESTIGATION OF THE MICROBIOTA}

In attempts to better understand the function of the human gut microbiota a well-defined animal model was generated by transplanting fresh or frozen fecal samples from a healthy adult human into young male C57BL/6J mice to establish a humanized mouse gut microbiota [17]. Culture-independent analysis showed stable and heritable colonization of bacteria reproducing much of the bacterial diversity found in humans. When mice with humanized gut microbiota were subjected to a "Western" diet, characterized by high fat and sugar contents, the structure of the microbiota changed within a single day, which affected the metabolic pathways in the microbiome and altered microbiome gene expression.

\section{MICROBIOTA AND HOST RESPONSE}

The gastrointestinal tract in mammals is dominated by four bacterial phyla, Firmicutes, Bacterioidetes, Actinobacteria and Proteobacteria, which produce a number of low molecular weight substances such as folate, butyrate, biotin and acetate [18]. Folate is a vitamin involved in many metabolic pathways affecting DNA replication, repair and methylation [19]. The shortchain fatty acid (SCFA) butyrate, produced by Faecalibacterium prausnitzii is a HDAC inhibitor [20]. Butyrate can activate silenced genes in cancer cells [21] and repress angiogenesis by reduced expression of pro-angiogenic factors such as EGF and HIF 1 $\alpha$ [22]. The concentration of butyrate in the colon is dependent on the diet and the intestinal microflora composition and can play an important role in cancer protection [1]. The vitamin biotin, supplied by the intestinal microbiota as mammalian cells cannot produce it, is important in epigenetic processes including gene expression regulation by histone proteins, DNA repair and chromatin structure modifications [23]. The gut microbiota also plays a crucial role in acetylation and deacetylation of histone and non-histone proteins affecting the regulation of gene expression [24]. For instance, oncogenes may utilize acetyl-CoA metabolism for alteration of chromatin to support growth [25].

Another contribution by the gut microbiota relates to the absorption and excretion of minerals such as zinc, iodine, selenium, cobalt and enzymatic cofactors [1]. Many metabolites act as cofactors for epigenetic enzymes involved in the regulation of RNA methylation and post-translational histone modifications, which in case of dysregulation can result in different diseases associated with epigenetic modifications [26].

\section{EPIGENETICS, FOOD AND THE GUT MICROBIOTA}

Maternal and neonatal nutrition has been demonstrated to have a major impact on the epigenome of the offspring also from the point of view that the dietary intake modulates the composition of the gut microbiota and the metabolites produced [27]. In this context, inflammatory bowels disease in premature infants was hypothesized to be caused by the interaction between the epigenome of the host and the initial intestinal colonizing microbiota [28]. It was demonstrated that exposure of immature enterocytes to probiotic and pathogenic bacteria resulted in differential modification of more than 200 DNA regions. Furthermore, prenatal exposure to dexamethasone showed alterations of the epigenome of the host after antenatal treatment with glucocorticoids in a mouse model. The expression profiles of genes associated with inflammatory responses and the intestinal barrier indicated DNA modification changes in 5 candidate genes verified by quantitative methylation-specific PCR (qMSP). Interestingly, epigenomic changes conditioned early microbiota colonization, which resulted in differential bacterial colonization at different taxonomic levels. Another study indicated that the composition of the gut microbiota is strongly influenced by the diet of infants [29]. The microbiota predominantly consists of Bifidobacteria in breast-fed infants, while introduction of solid food generates the development of a large number of other types of bacteria. In contrast, the microbiota of formula-fed children consists of a variety of bacteria including Streptococcus, Bacterioides and Clostridium genera as well as Bifidobacterium [29]. The gut microbiota is established by the age of two and remains relatively constant throughout life. However, the genetic content of the individual gut microbiota is dynamic, which is affected by the dietary intake. For instance, dietary fiber is converted into SCFAs and butyrate can induce cell differentiation [30], apoptosis [31] and hyperacetylation [32].

\section{THE MICROBIOTA AND DISEASE}

Studies on epigenetics have recently demonstrated an association between bacterial prominence and disease [33]. For instance, a correlation between 
differential methylation status of gene promoters and obesity and cardiovascular disease was found in pregnant women with Firmicutes and Bacteroidetes as the dominant gut bacteria.

Excessive consumption of red meat and fat has been associated with colorectal cancer due to the modulation of $\mathrm{N}$-nitroso compounds and heterocyclic aromatic amines [34]. Red meat also delivers Lcarnitine, which is digested by gut bacteria and converted into trimethylamine- $\mathrm{N}$-oxide (TMAO) indicated to cause atherosclerosis in mice [35]. In contrast, cruciferous vegetables such as cabbage, broccoli, kale and cauliflower contain high concentrations of fiber and their consummation has been associated with reduced risk of development of various cancers [36]. Furthermore, cruciferous vegetables, particularly broccoli, are rich in sulfur-containing glucosinolates, which are converted to biologically active compounds such as indoles, nitriles and isothiocyanates by the gut microbiome [37]. Isothiocyanates have been indicated to affect DNA methylation and are thereby linked to epigenetics. The glucosinolate of sulforaphane downregulates DNA methyltransferases leading to sitespecific $\mathrm{CpG}$ island demethylation of the telomerase reverse transcriptase (TERT) gene in breast cancer cell lines [38].

Studies on the composition of the gut microbiome have indicated that significant decreases in fecal SCFA concentrations such as acetate, proprionate and butyrate occurs in colon cancer patients compared to healthy individuals [39]. Moreover, the count of obligate anaerobes decreased significantly in colon cancer patients [40]. One approach of reducing the colon cancer risk has been to add probiotics to the diet [41]. For instance, short-lived metabolic mixtures isolated from milk that was fermented with strains of Lactobacillus bulgaricus and Streptococcus thermophilus have proven effective in deactivating etiologic risk factors of colon cancer. Another possibility is to provide cruciferous vegetables and green tea polyphenols to generate epigenetic modifications in the bacterial DNA or the genes they target [42]. Additionally, significant modifications of the microbiome compositions have been discovered in relation to breast cancer, where diarrhea and irritable bowel syndrome have been observed in patients undergoing chemotherapy [43]. Furthermore, stool microbiome and metabolome differences have been detected in colorectal cancer patients compared to healthy adults, in which several butyrate-producing bacteria were underrepresented in the group of cancer patients [44].
In contrast, the presence of the mucin-degrading species Akkermansia muciniphila was four times higher in cancer patients. Also, genotoxins and DNA-damaging superoxide radicals produced by Enterococcus faecalis have been suggested to contribute to the development of colorectal cancer [45]. Moreover, functions of the gut microbiota result in production of oncometabolites and tumor-suppressive metabolites, which is dependent on dietary factors [46]. In colorectal cancer patients epigenetic modifications accumulate leading to tumorigenesis. Dietary fiber metabolized to butyrate by gut bacteria may up-regulate tumorsuppressor genes in colorectal cancer cells. Altered composition of the gut microbiota achieved by diet modifications, application of probiotics, prebiotics, synbiotics and fecal transplantations have also been linked to inflammatory bowel disease [47].

The gut microbiome can also modulate the estrogen metabolism, which contributes to the ratio between recirculated and excreted estrogen [48]. Due to the influence of the gut microbiome on the estrabolome, increase in reabsorption of free estrogen may affect the development of estrogen-driven cancers such as breast, ovarian and endometrial cancers [49]. As catechol-O-methyltransferase (COMT) converts genotoxic catechol estrogens to their inactive methoxy derivatives 2-MeOE2 and 4-MeOE2 consumption of a plant-based diet (such as tomato) containing high levels of $O$-methyltransferases reduces the exposure to potentially mutagenic estrogen metabolites [50]. In the context of liver cancer, lipopolysacharide (LPS) from gut bacteria can activate toll-like receptor 4 (TLR4) [51]. Epigenetic regulation of TLR4 contributes to maintaining intestinal homeostasis and dietary input can be helpful for prevention of liver cancer [52].

Bacteria-derived neurotransmitters have recently been demonstrated to affect the autonomic nervous system with a role in enteric neuropathy [53]. Moreover, dietary intake, probiotic and antibiotic use have been demonstrated to regulate enteric neurotransmission through modulation of the gut microbiota.

\section{CONCLUSIONS AND FUTURE PROSPECTS}

Bioinformatics and genomics technology development has facilitated characterization of the human gut microbiota, which has clearly confirmed its importance for human well-being and disease prevention and therapy. The gut microbiota is responsible for the production of a large number of low molecular weight substances, which affect DNA 
replication and methylation leading to activation of silenced genes in cancer cells and repression of angiogenesis. In this context, the vitamin biotin plays an important role in epigenetic processes. The dietary intake has proven important also for the metabolism of the gut microbiota. The effect on the gut microbiota of breast-feeding in comparison to formula-fed infants is remarkable and although the composition is established by the age of two, environmental factors and particularly dietary intake can significantly modify the contents of the gut microbiota. Most importantly, the gut microbiota has been demonstrated to influence disease development through epigenetic modifications. Various cancers and other diseases have been postulated to be triggered by diet-induced activity of the gut microbiota often involving epigenetic functions.

Technology-driven analysis of the interaction of the gut microbiota, diet and epigenetics will certainly increase our understanding in the near future. Individual differences will play an important role based on genetics and genomics research, which will support generation of personalized diets and medicines. Related to drug development, the input of epigenetics will be significant due the possibility to discover new potential drug targets, but also the reversible nature of epigenetic mechanisms is a further attraction. Taken into account this, the interaction between the gut microbiota, nutrition and epigenetics will play an important part in preventive and therapeutic interventions.

\section{REFERENCES}

[1] Paul B, Barnes S, Demark-Wahnefried W, et al. Influences of diet and the gut microbiome on epigenetic modulation in cancer and other diseases. Clin Epigenetics 2015; 7: 112. http://dx.doi.org/10.1186/s13148-015-0144-7

[2] Takahashi K. Influence of bacteria on epigenetic gene control. Cell Mol Life Sci 2014; 71: 1045-54. http://dx.doi.org/10.1007/s00018-013-1487-x

[3] Kussman M, Van Bladeren PJ. The extended nutrigenomics - understanding the interplay between the genomes of food, gut microbes, and human host. Front Genet 2011; 2: 21. http://dx.doi.org/10.3389/fgene.2011.00021

[4] Noble D. Conrad Waddington and the origin of epigenetics. J Exp Biol 2015; 218: 816-8. http://dx.doi.org/10.1242/jeb.120071

[5] Su LJ, Mahabir S, Ellison GL, et al. Epigenetic contributions to the relationship between cancer and dietary intake of nutrients, bioactive food components and environmental toxicants. Front Genet 2012; 2: 1-11.

http://dx.doi.org/10.3389/fgene.2011.00091

[6] Fang M, Chen D, Yang CS. Dietary polyphenols may affect DNA methylation. J Nutr 2007; 137: 223S-228S.

[7] Boehm TL, Drahovsky D. Alteration of enzymatic methylation of DNA cytosines by chemical carcinogens; a mechanism involved in the initiation of carcinogenesis. J Natl Cancer Inst 1983; 71: 429-33.
[8] Costello JF, Plass C. Methylation matters. J Med Genet 2001; 38: 285-303.

http://dx.doi.org/10.1136/jmg.38.5.285

[9] Jones PA, Baylin SB. The epigenomics of cancer. Cell 2007; 128: 683-92.

http://dx.doi.org/10.1016/j.cell.2007.01.029

[10] Cheishvili D, Boureau L, Szyf M. DNA demethylation and invasive cancer: implications for therapeutics. $\mathrm{Br} J$ Pharmacol 2015; 172: 2705-15. http://dx.doi.org/10.1111/bph.12885

[11] Bollati V, Baccarelli A. Environmental epigenetics. Heredity 2010; 105: 105-12.

http://dx.doi.org/10.1038/hdy.2010.2

[12] Yang $\mathrm{PH}$, Zhang L, Zhang YJ, et al. HDAC6: physiological function and its selective inhibitors for cancer treatment. Drug Discov Ther 2013; 7: 233-42. http://dx.doi.org/10.5582/ddt.2013.v7.6.233

[13] Duenas-Gonzalez A, Coronel J, Cetina L, et al. Hydralazinevalproate: a repositioned drug combination for the epigenetic therapy of cancer. Expert Opin Drug Metab Toxicol 2014; 10: 1433-44.

http://dx.doi.org/10.1517/17425255.2014.947263

[14] Lundstrom K. MicroRNA in disease and gene therapy. Curr Drug Discov Technol 2011; 8: 76-86. http://dx.doi.org/10.2174/157016311795563857

[15] www.mirbase.org/cgi-bin/mirna-summary.pl?org=hsa (accessed February 25, 2016).

[16] Shah PP, Hutchinson LE, Kakar SS. Emerging role of microRNAs in diagnosis and treatment of various diseases including ovarian cancer. J Ovarian Res 2009; 2: 11. http://dx.doi.org/10.1186/1757-2215-2-11

[17] Turnbaugh PJ, Ridaura VK, Faith JJ, et al. The effect of diet on the human gut microbiome; a metagenomic analysis in humanized gnotobiotic mice. Sci Transl Med 2009; 1: 6ra 14.

[18] Jeffrey IB, O'Toole PW. Diet-microbiota interactions and their implications for healthy living. Nutrients 2013; 5: 234-52. http://dx.doi.org/10.3390/nu5010234

[19] Pompei A, Cordisco L, Amaretti A, et al. Folate production by bifidobacteria as a potential probiotic property. Appl Environ Microbiol 2007; 73: 179-85.

http://dx.doi.org/10.1128/AEM.01763-06

[20] Davie JR. Inhibition of histone deacetylase activity by butyrate. J Nutr 2003; 133: 24855-93.

[21] Cannani RB, Constanzo MD, Leone L. The epigenetic effects of butyrate: potential therapeutic implications for clinical practice. Clin Epigenetics 2012; 4: 4. http://dx.doi.org/10.1186/1868-7083-4-4

[22] Zgouras D, Wächterhäuser A, Frings $D$, et al. Butyrate impairs intestinal tumor cell-induced angiogenesis by inhibiting HIF-1 $\alpha$ nuclear translocation. Biohem Biophys Res Commun 2003; 300: 155-65.

http://dx.doi.org/10.1016/S0006-291X(02)02916-9

[23] Shenderov BA. Metabiotics: novel idea or natural development of probiotic conception. Microbiol Ecol Heealth Dis 2013; 24.

http://dx.doi.org/10.3402/mehd.v24i0.20399

[24] Peserico A, Simone C. Physical and functional HAT/HDAC interplay regulates protein acetylation balance. BioMed Res Int 2010; 2011: 371832.

[25] Carrer A, Wellen KE. Metabolism and epigenetics: a link cancer cells exploit. Curr Opin Biotechnol 2015; 34: 23-9. http://dx.doi.org/10.1016/j.copbio.2014.11.012

[26] Shenderov BA, Midtvedt T. Epigenomic programming: a future way to health? Microbiol. Ecol Health Dis 2014; 25. http://dx.doi.org/10.3402/mehd.v25.24145

[27] Turnbaugh PJ, Ridaura VK, Faith JJ, et al. The effect of diet on the human gut microbiome: a metagenomic analysis in humanized gnotobiotic mice. Sci Transl Med 2009; 6ra14. http://dx.doi.org/10.1126/scitransImed.3000322 
[28] Cortese R, Lu L, Yu Y, et al. Epigenome-microbiome crosstalk: a new paradigm influencing neonatal susceptibility for disease. Epigenetics 2016; 11: 205-15. http://dx.doi.org/10.1080/15592294.2016.1155011

[29] Favier CF, Vaughan EE, Vos WMD, et al. Molecular monitoring of succession of bacterial communities in human neonates. Appl Environ Microbiol 2002; 68: 219-26. http://dx.doi.org/10.1128/AEM.68.1.219-226.2002

[30] Augeron C, Laboisse CL. Emergence of permanently differentiated cell clones in a human colonic cancer cell line in culture after treatment with sodium butyrate. Cancer Res 1984; 44: 3961-9.

[31] Hague A, Manning AM, Hanlon KA, et al. Sodium butyrate induces apoptosis in human colonic tumour cell lines in a p53-independent pathway: implications for the possible role of dietary fibre in the prevention of large-bowel cancer. Int $\mathrm{J}$ Cancer 1993; 55: 498-505. http://dx.doi.org/10.1002/ijc.2910550329

[32] Candido EPM, Reeves R, Davie JR. Sodium butyrate inhibits histone deacetylation in cultured cells. Get Cell 1978; 14: 105-13.

http://dx.doi.org/10.1016/0092-8674(78)90305-7

[33] Kumar $\mathrm{H}$, Lund $\mathrm{R}$, Laiho $\mathrm{A}$, et al. Gut microbiota as an epigenetic regulator: pilot study based on whole-genome methylation analysis. MBio 2014; 5: e02113-4. http://dx.doi.org/10.1128/mBio.02113-14

[34] Hughes R, Cross AJ, Pollock JRA, et al. Dose-dependent effect of dietary meat on endogenous colonic N-nitrosation. Carcinogenesis 2001; 22: 199-202. http://dx.doi.org/10.1093/carcin/22.1.199

[35] Koeth RA, Wang Z, Levison BS, et al. Intestinal microbiota metabolism of Icarnitine, a nutrient in red meat, promotes atherosclerosis. Nat Med 2013; 19: 576-85.

http://dx.doi.org/10.1038/nm.3145

[36] Herr I, Buchler MW. Dietary constituents of broccoli and other cruciferous vegetables: implications for prevention and therapy of cancer. Cancer Treat Rev 2010; 36: 377-83. http://dx.doi.org/10.1016/i.ctrv.2010.01.002

[37] Navarro SL, Li F, Lampe JW. Mechanisms of action of isothiocyanates in cancer chemoprevention: an update. Food Function 2011; 2: 578-87. http://dx.doi.org/10.1039/c1fo10114e

[38] Meeran SM, Patel SN, Tollefsbol TO. Sulforaphane causes epigenetic repression of hTERT expression in human breast cancer cell lines. PLoS One 2010; 5: e11457. http://dx.doi.org/10.1371/journal.pone.0011457

[39] Ohigashi S, Sudo K, Kbayashi D, et al. Changes of the intestinal microbiota, short chain fatty acids, and fecal $\mathrm{pH}$ in patients with colorectal cancer. Dig Dis Sci 2013; 58: 171726.

http://dx.doi.org/10.1007/s10620-012-2526-4

[40] McGarr SE, Ridlon JM, Hylemon PB. Diet, anaerobic bacterial metabolism, and colon cancer: a review of the literature. J Clin Gastroenterol 2005; 39: 98-109.
[41] Wollowski I, Rechkemmer G, Pool-Zobel BI. Protective role of probiotics and prebiotics in colon cancer. Am J Clin Nutr 2001; 73: 451s.

[42] Hullar MA, Fu BC. Diet, the gut microbiome and epigenetics. Cancer J 2014; 20: 170.

\section{http://dx.doi.org/10.1097/PPO.0000000000000053}

[43] Stringer AM, Gibson RJ, Bowen JM, et al. Chemotherapyinduced modifications to gastrointestinal microflora: evidence and implications of change. Curr Drug Metab 2009; 10: 7983.

http://dx.doi.org/10.2174/138920009787048419

[44] Weir TL, Manter DK, Sheflin AM, et al. Stool microbiome and metabolome differences between colorectal cancer patients and healthy adults. PLoS One 2013; 8: e70803. http://dx.doi.org/10.1371/journal.pone.0070803

[45] Gao Z, Guo B, Gao R, et al. Microbiota disbiosis is associated with colorectal cancer. Front Microbiol 2015; 6: 20. http://dx.doi.org/10.3389/fmicb.2015.00020

[46] Bultman SJ. Interplay between diet, gut microbiota epigenetic events, and colorectal cancer. Mol Nutr Food Res 2016.

http://dx.doi.org/10.1002/mnfr.201500902

[47] Serban DE. Microbiota in inflammatory bowels disease pathogenesis and therapy: is it all about diet? Nutr Clin Pract 2015; 30: 760-79.

http://dx.doi.org/10.1177/0884533615606898

[48] Fuhrman BJ, Feigelson HS, Flores R, et al. Associations of the fecal microbiome with urinary estrogens and estrogen metabolites in postmenopausal women. J Clin Endicrinol Metabol 2014; 99: 46320-40. http://dx.doi.org/10.1210/jc.2014-2222

[49] Plottel CS, Blaser MJ. Microbiome and malignancy. Cell Host Microbe 2011; 10: 324-35.

http://dx.doi.org/10.1016/j.chom.2011.10.003

[50] Mageroy $\mathrm{MH}$, Tieman DM, Floystad A, et al. Solarium lycopersicum catechol-O-methyltransferase involved in synthesis of the flavor molecule gualacol. Plant J 2012; 69: 1043-51.

http://dx.doi.org/10.1111/j.1365-313X.2011.04854.x

[51] Dapito DH, Mencin A, Gwak GY, et al. Promotion of hepatocellular carcinoma by the intestinal microbiota and TLR4. Cancer Cell 2012; 21: 504-16. http://dx.doi.org/10.1016/j.ccr.2012.02.007

[52] Takahashi K, Sugi Y, Nakano K, et al. Epigenetic control of the host gene by commensal bacteria in large intestinal epithelial cells. J Biol Chem 2011; 286: 35755-62. http://dx.doi.org/10.1074/jbc.M111.271007

[53] Savidge TC. Epigenetic regulation of enteric neurotransmission by gut microbiota. Front Cell Neurosci 2016; 9: 503.

http://dx.doi.org/10.3389/fncel.2015.00503 